\title{
Evaluation of Seasonal Serum Level of Estradiol and Progesterone Hormones in Iranian Female Caucasian Viper
}

\author{
Saeedeh Fani ${ }^{1}$, Qulam Hussein Vaezi ${ }^{1}$, Fatemeh Todehdehghan ${ }^{2,}$ * \\ ${ }^{1}$ Basic Sciences Faculty, Islamic Azad University, Damqan, Iran \\ ${ }^{2}$ Venomous Animals Department, Razi Vaccine \& Serum Research institute, Karaj, Agricultural Research, Education and Extension \\ Organization (AREEO), Tehran, Iran
}

Email address:

F.Todehdehghan@rvsri.ac.ir (F. Todehdehghan)

${ }^{*}$ Corresponding author

To cite this article:

Saeedeh Fani, Qulam Hussein Vaezi, Fatemeh Todehdehghan. Evaluation of Seasonal Serum Level of Estradiol and Progesterone Hormones in Iranian Female Caucasian Viper. Animal and Veterinary Sciences. Vol. 5, No. 1, 2017, pp. 21-26. doi: 10.11648/j.avs.20170501.14

Received: October 23, 2016; Accepted: February 13, 2017; Published: March 4, 2017

\begin{abstract}
Steroids hormones have a basic role in animals' reproductive activity and their secretion amounts are changed during the year with animal physiological conditions. There is no study reporting Iranian female snake's hormones controlling reproductive activity. In this study the estradiol (E2) and progesterone (P4) hormones level in serum samples of 26 female Caucasian vipers were examined by electrochemiluminescence (ECL). The results show the average concentration of estradiol (E2) hormone in the autumn $(157.2 \pm 47.53 \mathrm{nmol} / \mathrm{Lt}$ ) is less than the early winter (December-January), $318.33 \pm 156 \mathrm{nmol} / 1$ $(p \leq 0.1)$ and again the concentration of this hormone reduced in the summer, $188.94 \pm 33.57 \mathrm{nmol} / \mathrm{Lt}(\mathrm{p} \leq 0.78)$. The average concentration of P4 hormone in the autumn was $0.45 \pm 0.14 \mathrm{nmol} / \mathrm{Lt}$ and in winter was $0.96 \pm 0.57 \mathrm{nmol} / \mathrm{Lt}$, that show increasing process $(\mathrm{p} \leq 0.22)$. The average concentration of this hormone is decreasing in the summer, $0.82 \pm 0.23 \mathrm{nmol} / \mathrm{Lt}$ as compared to the winter $(\mathrm{p} \leq 0.78)$. In the fertile snacks the amount of serums estradiol is increased during the vitellogenesis and progesterone is increased during pregnancy and the amount of these hormones is low throughout the year in unfertile snacks. According to these hormones changing during the seasons it seems that the Iranian Caucasian viper from Lar area in Tehran province, during the winter season is in the vitellogenesis phase and summer is the pregnancy time and the autumn is the time of postpartum. Although the maximum amount of progesterone is inconsistent with the winter but like this case is reported before.
\end{abstract}

Keywords: Female Viper, Steroid Hormone, Season Changes, Serum, Electrochemiluminescence

\section{Introduction}

Steroid hormones mediate the reproductive cycles of snakes like other vertebrates $[25,24]$. The roles of these hormones in snakes are complex and are still not fully understood. The mating patterns of pit vipers are complex. They can vary within family, genus, and even species [3]. Such diversity is possible due to the fact that, in most snakes, reproductive behaviors are not restricted to the time of ovulation. Female snakes can store sperm from the breeding season until the time of ovulation. In some species, females are able to store sperm for several months (long term sperm storage, LTSS); others store sperm for only a few weeks (short term sperm storage, STSS) $[5,15,22]$. In all temperate vipers studied, ovulation occurs in the early summer and parturition occurs in the fall [3]. Ovulation and mating generally take place at the time of year that will result in offspring birth, at a time that optimizes survival. Female viper species, in addition to differing in the timing of mating, differ in the timing of vitellogenesis (i.e., production of the protein vitellogenin, which stimulates follicular yolk deposition). Only one temperate pit viper studied, C. atrox, initiates vitellogenesis in the spring (Type I vitellogenesis) [23]. All other species studied begin vitellogenesis in the summer or fall, pause follicular activity over winter, and resume and complete vitellogenesis in the spring and early summer (Type II vitellogenesis)[3]. The timing of other events in the reproductive cycle (e.g. ovulation, and parturition) is conserved, with females ovulating in early summer and giving birth to live young in late summer [3].

Estradiol and Progesterone 
Many studies have investigated sex steroid hormone concentrations of species with known mating systems in an effort to correlate steroid hormone concentrations with events of the reproductive cycle $[4,9,16,17,18,19,26,29]$.

Estradiol is produced by ovarian granulosa cells and it seems that it is the first stimulant for mating behavior (estrus period) and yolk protein synthesis along ovulation in female reptiles [8]. The vitellogenesis is occurring in viviparous and egg-laying vertebrates and it is the way for yolk protein sediment and synthesis in follicles growth [8] P4 is another steroid hormone ceases the vitellogenesis and maintain the pregnancy or development. Progesterone is produced by granulosa cells in ovary follicles, in productive female reptiles, male's adrenal glands and non-productive females [9]. Estradiol-17 (E2) is the main estrogen in blood circulation and is essential for natural ovary growth in many vertebrates $[10,13]$. There is relationship between reproductive events and the concentration of steroids hormones in free range pit vipers (Viperidae, Crotalinae), of the New world species. In this species concentration of E2 is at its peak in vitellogenesis (winter) and p4 is high during pregnancy (late winter, spring and summer). In a study by Taylor et al [26] the relation between concentration of steroids hormones and events of vertebrates reproductive cycle including mating behavior, spermatogenesis and vitellogenesis in rattlesnake of North waters, have been investigated. It seems that the vitellogenesis time in female diamond-backed rattlesnake is in late autumn and the peak of estradiol is in winter [26]. Reproductive female $C$. oreganus of Northern Pacific Rattle snake exhibit breeding behaviors in the spring and late summer/fall. During these seasons, several females had high E2, T(testosterone), and DHT(dihydro testosterone) concentrations. These hormones have all been implicated as role players in the production of breeding behavior and/or vitellogenesis in female reptiles. There was a large amount of within-season variation in the concentrations of all quantified hormones [12]. In general, the relationship between steroid hormones and reproduction in snakes shows that plasma estradiol (E2) is high during vitellogenesis that reflects its role in stimulating the production of vitellogenin by liver. Taylor et al [26] describes pattern in female diamond-backed rattlesnakes that if females do not reproduce within a year, the concentrations of T, E2 and P4 are reduced during the year, but if female is reproducing, the amount of E2 raises in March to June and especially in April and May. This is coincided with the vitellogenesis in rattlesnake species and many other species in the temperate area. The concentration of $\mathrm{T}$ in fertile female snakes is low throughout the year with little increase in the spring, which is because of the production of E2. Progesterone level in the fertile females C. atroxis is high in May to August and June, reaches a peak in concurrent with the pregnancy [14]. There is no clear difference between reproductive and non-reproductive Aspic female viper mating season in France and the reproduction pattern is same as C.atrox (vitellogenesis in spring and give birth in late summer). Saint Girons et al,
[14] have reported that plasma P4 concentration in aspic viper reproduction is incompatible. However, other studies shows that the plasma $\mathrm{P} 4$ concentration is high in females in May and August during pregnancy and decreases in September (after delivery), and increases again in winter. In female Chinese green tree viper, Trimeresurus stejnegeri stejnegeri, E2 concentration increases little during vitellogenesis but $\mathrm{p} 4$ concentration increases dramatically during pregnancy [28]. Almeida Santos et al.,[4] found that there is relationship between the concentration of sexual steroids and reproductive events (reproduction) in the females snakes living in northern waters in southeastern Brazil. In this species concentration of E2 is at its peak in vitellogenesis (winter) and p4 is high during pregnancy (end of winter, spring and summer). While both hormones level are low in non-fertile females during the year. In studies of the reproductive cycle of rattlesnakes in North Crotalus oreganus [12] showed that different concentrations of progesterone do not differ in females. But it is likely that during pregnancy in the summer, $\mathrm{P} 4$ concentration is high. In these females concentrations were positively correlated with the amount of T and DHT. P4 and E2 concentrations also has a positive correlation with $\mathrm{T}$. Progesterone concentration was very low in most samples. According to a study by Taylor et al [26], in viper snakes, the limits of sex hormones in females are shown high. In some females, E2 concentration is at high level in spring and autumn, at the same time mating with large follicular diameter, indicating the vitellogenesis time. Females with high concentrations of E2 also have high concentrations of T and DHT. According to a study on Agkistrodon piscivorus [21], E2 levels in snakes females at the presence of their young and those were kept separate of their babies, showed not significant differences between the two groups during the sampling period. Also the low level of concentration of E2 is expected to promote vitellogenin production by the liver [8]. In other study on the viper snakes it was observed that E2 increases only during vitellogenesis [24].

\section{Materials and Methods}

\subsection{The Geographical Condition of Lar}

The Caucasian vipers were collected from Lar area in the central Alborz mountains in the South Western of Damavand hill side between Mazandaran and Tehran provinces (Latifi, 2000 ), this area is located at $32^{\prime}-51^{\circ}, 32^{\prime}-52^{\circ}$ East longitude and $52^{\prime}-35^{\circ}, 50^{\prime}-36^{\circ}$ of North latitude and of the North, West, South and East is restricted respectively to Noor mountains, Khatun Bargah and Garmabdar, Lavasanat highlands and Damavand mountain and Ploor area that is considered cold mountainous watery habitats. The average of annual temperatures in the winter and summer seasons respectively is $-37^{\circ} \mathrm{C}$ and $+31^{\circ} \mathrm{C}$. The coldest months of year are December-January and January-February and the hottest months are June-July and July-August. The most rainfalls are in February-March month that is $95 \mathrm{ml}$. 


\subsection{Animal Housing}

The 26 female Caucasian vipers were collected from Lar area at the spring season from April-May and August-September 2014. After parasite decontamination (Cypermethrin 100 emulsion) of vipers and passing quarantine time, they were kept in a vivarium under conventional conditions (figure 1). The blood sampling was performed and serums (centrifuged in $1500 \mathrm{rpm}$, at $4^{\circ} \mathrm{C}$ for $15 \mathrm{~min}$ ) were prepared.

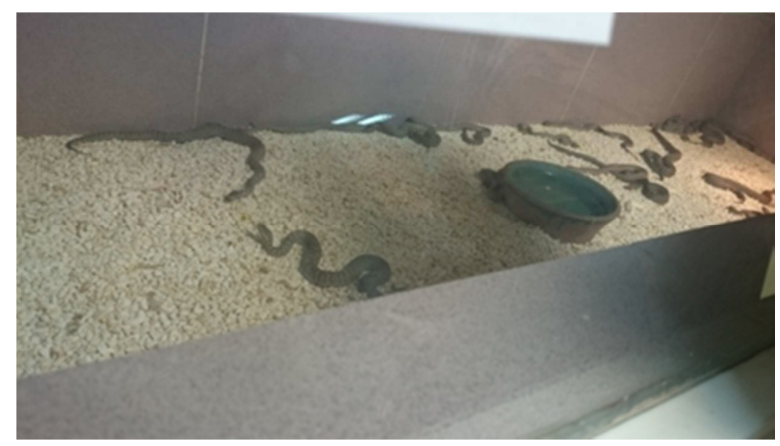

Figure 1. Snakes vivarium.

\subsection{Estradiol and Progesterone Assessment}

Blood samples were collected from ventral tail vein of snakes in the tubes containing EDTA. The samples were centrifuged (in $1500 \mathrm{rpm}$, at $4^{\circ} \mathrm{C}$ for $15 \mathrm{~min}$ ), and the serum was stored at $-20^{\circ} \mathrm{C}$ until assay.

The assay of hormones was carried out by a method of competition immunological type in heterogeneous phase or electrochemiluminesence. It is revealed by ECL (substrate: ruthenium) on the automat. The antibodies of capture and revelation are monoclonal specific to progesterone and estrogen of human origin. The total duration of the assay is $18 \mathrm{~min}$. In the first incubation, $30 \mu \mathrm{l}$ of serum sample was added to a mixture of the antibody antiprogesterone/estradiol labeled with biotin and the peptideprogesterone/estradiol labeled with ruthenium. In the second incubation, the streptavidin was added into the reaction well. The immunological complex was fixed at the solid phase by a complex streptavidin-biotin. The quantity of hormone linked at the solid phase is inversely proportional to the hormone concentration in the sample. The reaction mixture was transferred in the measuring cell. The micro-particles were maintained in the electrode level by a magnet. The elimination of the free fraction was carried out with a washing buffer. A potential difference applied to the electrode, starts the production of luminescence that was measured by a photomultiplier. Parameters of validation including minimal limit of detection (MDL), reproducibility (coefficient of variation inter-and intra-assay), accuracy and parallelism were taken into consideration in this study.

\section{Results}

\subsection{The Serum Level of Estradiol Hormone}

The mean level of E2 concentration in the fall was
157.2 $\pm 47.53 \mathrm{nmol} / \mathrm{Lt}$ and in early winter (DecemberJanuary) was $318.33 \pm 156 \mathrm{nmol} / \mathrm{Lt}$ that shows significant increase in the level of this hormone in the winter at $\mathrm{P} \leq 0.01$. By increasing temperature in the summer concentration of E2 was $188.94 \pm 33.57 \mathrm{nmol} / \mathrm{Lt}$, we faced a decrease in the level of this hormone as compare to the winter, although the difference was not significant $(\mathrm{P} \leq 0.01)$. The concentration of estradiol in the three seasons of year is shown in the figure 2.

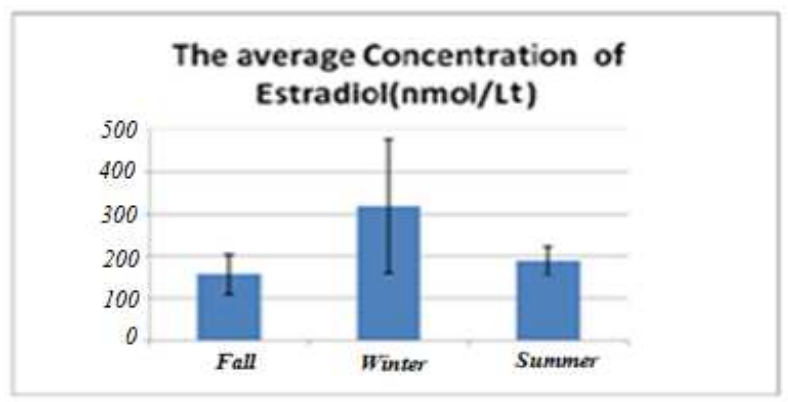

Figure 2. The average concentration of Estradiol (E2) in the three seasons Fall, winter and summer in female Caucasian viper ( \pm SEM).

\subsection{The Serum Levels of Progesterone Hormone}

The concentration of $\mathrm{P} 4$ hormone was low in the fall, 0.45 $\pm 0.14 \mathrm{nmol} / \mathrm{Lt}$ and in the winter was $0.96 \pm 0.57 \mathrm{nmol} / \mathrm{Lt}$, that was higher than fall but the difference wasn't significant at $\mathrm{P} \leq 0.2$. In the summer level of $\mathrm{P} 4$ was $0.82 \pm 0.23 \mathrm{nmol} / \mathrm{Lt}$, and comparatively lower than winter and higher than fall although differences were not significant at $\mathrm{P} \leq 0.05$ (figure 3 ).

However we have observed rising trend of P4 and E2 concentrations in female Caucasian viper at the winter at the time of hibernation.

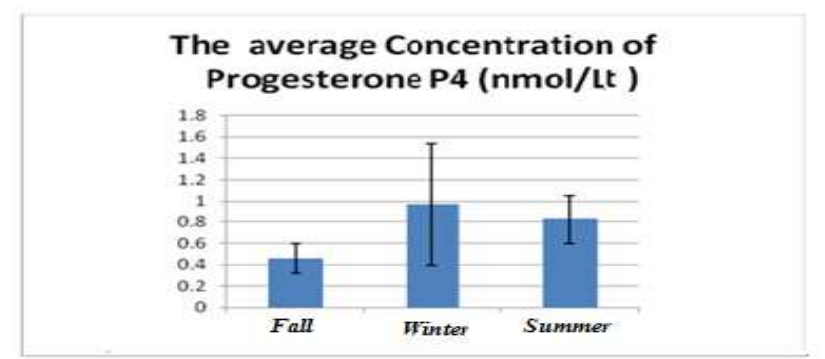

Figure 3. The average concentration of progestron $(P 4)$ in the three seasons Fall, winter and summer in female Caucasian viper ( \pm SEM).

\section{Discussion}

Many of physiological and reproductive behaviors in animals are mediated by steroid hormones. In many vertebrates the steroid hormones are very important for ovary differentiation, growth and development and also necessary for growth promotion and female's reproductive system differentiation [10]. The steroid hormones play an important role in reproductive biology of vertebrates including reptiles. The relation between steroids hormones and reproductive events in the female snacks shows that plasma E2 is high along vitellogenesis that reflect its role in stimulating 
production of vitellogenin by liver. The plasma P4 that quite often raising during pregnancy in viviparous snakes indicates its role in pregnancy maintenance. Taylor etal, [26] described the hormonal pattern of female diamond-backed rattle snakes that if females don't ovulate or reproduce during one year, the concentrations of T, E2 and P4 are low, but if snake has reproduction the level of E2 in March to June and specially in April and May months is high. This time is coinciding with vitellogenesis of rattlesnake species and more other species at temperate region. In the vipers including pit vipers, secondary vitellogenesis occurs from the early autumn till early spring [27], sperms may store in reproductive tract of female or male viper in the winter and ovulation, fertilization and embryo formation occur in the spring season [27]. In several species of temperate regions snakes specially vipers, mating may perform in summer and sperms store for 6 months or more before ovulation in female oviduct [27]. As it is provided in the result, the E2 concentration in female Caucasian vipers at the fall season is lower than winter, just at the beginning of vitellogenesis in snakes. Following of vitellogenesis the, E2 hormone concentration is increasing in the winter that is similar to reproductive cycle of the Neotropical Crotalus durissus terrificus [4]. Almeida Santos et al., [4] and Bonnet et al.,[6] have reported that in viviparous snake Vipera aspis, estradiol reached high levels during vitellogenesis $\left(4.8+/-4.0 \mathrm{ng} / \mathrm{ml}^{-1}\right)$, and progesterone levels increased during gestation, from $3.7 \mathrm{ng} / \mathrm{ml}^{-1}$ before gestation to $18.7 \mathrm{ng} / \mathrm{ml}^{-1}$ at mid gestation. So it seems that female Caucasian viper vitellogenesis ceased at late fall, like diamond-backed female snake [26] and increase of E2 concentration (vitellogenesis) at winter is like rattlesnake of the North waters [5]. We face decreasing level of E2 at summer with temperature rising and ending of vitellogenesis period. In the aspic viper (Vipera aspis), P4 concentrations are low in the follicular phase (vitellogenesis), and rise during the luteal (post-ovulation) phase until parturition [25]. This supports the hypothesis that P4 is an antagonist of E2 and acts to redirect hepatocytes away from synthesis of vitellogenic proteins and toward other functions [25]. Progestrone suppresses the vitellogenesis and maintain the pregnancy [8]. At the present study the maximum amount of progesterone is inconsistent with the winter but like this case is reported before. In other study, plasma P4 concentrations of reproductive female V. aspis are elevated in May through August (gestation), decrease in September (after parturition), and rise again during winter [6]. The concentration of $\mathrm{P} 4$ in female Caucasian viper of the Lar area was low in fall and higher at summer that is coincided with the pregnancy time and postparturation [20] that resembles to female rattlesnakes of the North waters at East South of Brazi [4]. Shakoori et al [20] have reported birth of 3-5 young Caucasian vipers of Iran in the late summer. Saint-Gironset al [14] shows that the plasma P4 concentration in females that have done reproduction, during gestation is high between May till August and after giving birth decreased at September (End of the summer and the first of autumn). However, studies of viviparous snakes reveal that exogenous administration of progesterone (p) has no effect on gestation length, suggesting some fetal control of parturition [6]. It appears that $\mathrm{P}$ is directly involved in the maintenance of pregnancy in reptiles; however, a drop in $\mathrm{P}$ concentrations may not be the primary stimulus for parturition in all species $[6,7,26]$. In this form with decreasing temperature during the winter (Vitellogenesis) and hibernation period, the concentration of sexual hormones are high may be due to low rates of metabolic clearance at low temperatures. Steroid hormone concentrations have been quantified in female pit vipers from two populations of $C$. durissus, [4] and C. atrox, [26]. These studies focused on the hormones E2 and P. 17 $\beta$-estadiol is elevated during secondary vitellogenesis in both species. Progesterone concentrations were basal at this time, which supports the hypothesis that P and E2 may be antagonists. Pregnancy profiles in these two species are similar, with peak $\mathrm{P}$ concentrations recorded early in gestation followed by a steady decline until parturition. 17 $\beta$-estradiol is basal during pregnancy in both species. Crotalus atrox in the Sonoran Desert displays a vitellogenic pattern very different from most rattlesnakes. Most rattlesnakes initiate secondary vitellogenesis in the fall before a reproductive year [3]. This cycle would presumably coincide with elevated E2 levels in both the fall and spring. Crotalus atrox in the Sonoran Desert utilize Type I vitellogenesis and have a unimodal E2 profile with basal levels recorded during fall breeding season. The proximate cue for breeding behavior during the fall breeding season is unknown. To date, an E2 profile has never been recorded for a female pit viper that initiates vitellogenesis in the fall. Smith et al [23], investigated levels of plasma progesterone (P4), 17 $\beta$-estradiol (E2), testosterone (T), and corticosterone (CORT) during gestation and post-birth periods in wild-collected female copperhead snakes (Viperidae; Agkistrodon contortrix). They reported progesterone showed significant changes during gestation, with the highest levels at the onset of sampling (50 days prior to birth); P4 progressively declined up to parturition, and basal levels were observed thereafter. At the onset of sampling, E2 was at peak levels and fell sharply at 30 days prior to birth, a trend observed throughout the post-birth sampling period and there was a significant relationship between duration of labor and litter size; however, although levels of CORT did not achieve significance, there was a positive trend with litter size [23].

\section{Conclusion}

Based on our observation during winter season the amount of E2 concentration rising in Iranian female Caucasian viper from Lar region, may be concurrent with vitellogenesis and with temperature decreasing, mating season begins and pregnancy occur at summer (according our previous work, [20]) and with increasing P4 level (the vitellogenesis stop there is a decrease in serum E2 during gestation and postparturition) pregnancy is maintained. However, further investigation is required on hormones in both sexes if an understanding of the relationship between steroid hormones 
and reproductive cycle of pit vipers is ever to be achieved.

\section{References}

[1] Afsharzadeh N. Shiravi A. H. and Todehdehghan F. 2015. Seasonal changes in ovarian follicle growth in Iran viper (Vipera albicornuta.) Advances in Biology, 2015, 9-19.

[2] Aldridge R. D. and Arackal, A. A. 2005. Reproductive biology and stressof captivity in male brown treesnakes (Boiga irregularis) on Guam. Aust. J. Zool. 53, 249-256.

[3] Aldridge R. D., Duvall D., 2002. Evolution of the mating season in the pitvipers of North America. Herpetol. Monographs 16, 1-25.

[4] Almeida-Santos S. M., Abdalla F. M. F., Silveira P. F., Breno, Y. N. and Saloma o, M. G. 2004a. Reproductive cycle of the Neotropical Crotalus durissus terrificus: I. Seasonal levels and interplay between steroid hormones and vasotocinase. Gen. Comp. Endocrinol., 139, 143-150.

[5] Almeida-Santos S. M., Laporta-Ferreira L. L., Antoniazzi M. M., Jared C. 2004b. Sperm storage in males of the snake Crotalus durissus terrificus (Crotalinae: Viperidae) in southeastern Brazil. Comp. Biochem. Phys. 139, 169-174.

[6] Bonnet X., Naulleau G., Bradshaw D., Shine R. 2001. Changes in plasma progesterone in relation to vitellogenesis and gestation in the viviparous snake Vipera aspis. Gen. Comp. Endocrinol. 121, 84-94.

[7] Callard I. P., Hirsch M., 1976. The influence of oestradiol-17 $\beta$ and progesterone on the contractility of the oviduct of the turtle, Chrysemys picta, in vitro. J. Endocrinol. 68, 147-152.

[8] Callard I. P., Riley D., Perez L. 1990. Vertebrate vitellogenesis: molecular model for multi hormonal control of gene regulation. Prog. Clin. Biol. Res. 342, 343-348.

[9] Graham, S. P., Earley, R. L., Hoss, S. K., Schuett, G. W., 2008. The reproductive biology of male cottonmouths (Agkistrodon piscivorus): Do plasma steroid hormones predict the mating season? Gen. Comp. Endocrinol. 159, 226-235.

[10] Katsu Y., Matsubara, K., Kohno S., Matsuda Y., Toriba M., Oka K., Louis J. Guillette, J. R.., Ohta Y., and Iguchi T. 2010. Molecular cloning, characterization, and chromosome mapping of reptilian estrogen receptors. Endocrinology, 151 (12): $5710-5720$

[11] Latifi M. 2000. Iran snakes, environment maintenance organization, pp. 10-461.

[12] Lind C. M., Husak J. F., Eikenaar C., Moore I. T., Taylor E. N. 2010. The relationship between plasma steroid hormone concentrations and the reproductive cycle in the Northern Pacific rattlesnake, Crotalus oreganus, Gen. Comp. Endocrinol.166, 590-599.

[13] Ramsay J. M., WatralV., SchreckC. B., Kent M. L. 2009. Husbandry stress exacerbates mycobacterial infections in adult zebrafish, Danio rerio (Hamilton). 10, 1365-2761.

[14] Saint Girons H., Bradshaw S. D., Bradshaw F. J. 1993. Sexual activity and plasma levels of sex steroids in the aspic viper Vipera aspis L. (Reptilia, Viperidae). Gen Comp Endocrinol 91: 287-297.
[15] Schuett, G. W., 1992. Is long-term sperm storage an important component of the reproductive biology of temperate pitvipers? In: Campbell, J. A., Brodie, E. D., Jr. (Eds.), Biology of the Pitvipers. Selva, Tyler, Texas, pp. 169-184.

[16] Schuett G. W., Harlow H. J., Rose J. D., Van Kirk E. A., Murdoch W. J., 1997. Annualcycle of testosterone in male copperheads, Agkistrodon contortix (Serpentes: Viperidae): relationship to timing of spermatogenesis, mating, and agonistic behavior. Gen. Comp. Endocrinol. 105, 417-424.

[17] Schuett G. W., Carlisle S. L., Holycross A. T., OLeile J. K., Hardy Sr D. L., Van Kirk E. A., Murdoch W. J., 2002. Mating system of male Mojave Rattlesnakes (Crotalusscutulatus): seasonal timing of mating, agonistic behavior, spermatogenesis, sexualsegment of the kidney, and plasma sex steroids. In: Schuett, G. W., Hoggren, M., Douglas, M. E., Greene, H. W. (Eds.), Biology of the Vipers. Eagle Mountain Publishing, Eagle Mountain, Utah, pp. 515-532.

[18] Schuett G. W., Hardy Sr D. L., Greene H. W., Earley R. L., Grober M. S., Van KirkE. A., Murdoch W. J., 2005. Sympatric rattlesnakes with contrasting mating systems show differences in seasonal patterns of plasma sex steroids. Anim. Behav. 70, 257-266.

[19] Schuett, G. W., Repp, R. A., Taylor, E. N., DeNardo, D. F., Earley, R. L., Van Kirk, E. A., Murdoch, W. J., 2006. Winter profile of plasma sex steroid levels in free-living male western diamond-backed rattlesnakes, Crotalus atrox (Serpentes: Viperidae). Gen. Comp. Endocrinol. 149, 72-80.

[20] ShakooriS., Todehdehghan F., Shiravi A. H., Hojati V. 2015. The assessment of captive breeding in the Caucasian viper (Gloydius halys caucasicus) in Iran. Journal of Entomology and Zoology Studies 3 (2): 257-259.

[21] Shannon K., Hoss A., Mark J. Garcia B., Ryan L., Earley B., Rulon W., Clark A. 2014. Fine-scale hormonal patterns associated with birth and maternal care in the cottonmouth (Agkistrodon piscivorus), a North American pit viper snake. Gen. Comp. Endocrinol. 208, 85-93.

[22] SiegelD. S., Sever D. M., Rheubert J. L., Gribbins K. M. 2009. Reproductive biology of Agkistrodon piscivorus Lacépède (Squamata, Serpents, Viperidae, Crotalinae). Herpetol. Monogr. 23, 74-107.

[23] Smith C. F., Schuett G. W., and Hoss S. K. 2012. Reproduction in female copperhead snakes (Agkistrodon contortrix): plasma steroid profiles during gestation and postbirth periods. Zoological Science 29 (4): 273-279.

[24] Taylor EN, DeNardo D. F. 2011. Hormone and reproductive cycles in snakes. In "Hormones and Reproduction in Vertebrates, Vol. 3, Reptiles" Ed by DO Norris, KH Lopez, Acade mic Press, San Diego, California, pp 355-372.

[25] Taylor E. N., DeNardo, D. F., 2010. Hormones and reproductive cycles of snakes, In"Hormones and Reproduction of Vertebrates, (D. O. Norris and K. H. Lopez,eds.), San Diego, Elsevier.

[26] Taylor, E. N., DeNardo, D. F., Jennings, D. H. 2004. Seasonal steroid hormone levels and their relation to reproduction in the western diamond-backed rattlesnake, Crotalus atrox (Serpentes: Viperidae). Gen. Comp. Endocrinol.136, 328-337.

[27] Todehdehqan. F. 2014. Tavalod Marha, Frst edition, Avaye Fahim publication, Tehran, Iran. 
26 Saeedeh Fani et al.: Evaluation of Seasonal Serum Level of Estradiol and Progesterone Hormones in Iranian Female Caucasian Viper

[28] Tsai TS, MC Tu. 2001. Reproductive cycle of female Chinese green tree viper, Trimeresurus stejnegeri stejnegeri in northern Taiwan. Herpetologica 57: 157-168.
[29] Zaidan III, F., Kreider, D. L., Beaupre, S. J., 2003. Testosterone cycles and reproductive energetics: implications for northern range limits of the cottonmouth (Agkistrodon piscivorus leucostoma). Copeia 2003, 231-240. 